\title{
Porcine cytochrome P450 and metabolism
}

Skaanild, Mette Tingleff

Published in:

Current Pharmaceutical Design

DOI:

$10.2174 / 138161206776361183$

Publication date:

2006

Document version

Early version, also known as pre-print

Citation for published version (APA):

Skaanild, M. T. (2006). Porcine cytochrome P450 and metabolism. Current Pharmaceutical Design, 12(11), 1421-1427. https://doi.org/10.2174/138161206776361183 


\title{
Porcine Cytochrome P450 and Metabolism
}

\author{
Mette Tingleff Skaanild \\ The Royal Veterinary and Agricultural University \\ Department of Veterinary Pathobiology \\ Ridebanevej 9 \\ DK-1870 Frederiksberg
}

Denmark

Mette Tingleff Skaanild

The Royal Veterinary and Agricultural University

Department of Veterinary Pathobiology

Ridebanevej 9

DK-1870 Frederiksberg

Denmark

E-Mail: $\underline{\text { mts@kvl.dk }}$

Fax: + 4535353514

Phone: + 4535283175 


\begin{abstract}
The pig and especially the minipig are becoming increasingly used as a test animal both in pharmacological and toxicological testing of new compounds. The minipig is used because of its size, it is easy to handle and less test substrate is required. When using an animal species for testing it is of importance to know if the test animal's posses the same abilities to metabolize drugs as humans. Some of the P450 enzymes have been characterized in the pig regarding substrate specificity, inhibition and regulation. The porcine enzymes CYP1A, CYP2A and CYP3A all metabolize the same test substrates as the human enzymes, whereas the enzymes CYP2B, CYP2D, and CYP2E in pig on the other hand seem to be different from the human enzymes concerning metabolism of the well know test substrates. Some of the porcine enzymes have been sequenced i.e. CYP1A, CYP2A, CYP2B, CYP2D, CYP2E and CYP3A and not surprisingly the porcine CYPs that metabolize the human test substrates are about $75 \%$ identical in cDNA sequences.

What is needed is inhibitory antibodies against each of the porcine enzymes, in order to test whether a test compound is metabolized by one or the other enzyme. Until now chemical inhibitors have been used, but they are rarely $100 \%$ specific. Anti-human inhibitory antibodies have also been used, but they may not recognize the porcine enzyme and therefore will not inhibit the reaction. Antibodies for immunoblotting would also make it possible to estimate how much of the total P450 the individual enzymes comprise. From what is known about the porcine P450, it can be concluded that the pig seems to be a good test species if CYP1A, CYP2A or CYP3A are involved in the metabolism of the test compound, depending on the contribution of other enzymes in competing pathways.
\end{abstract}

Keywords: Cytochrome P450, microsomes, liver, porcine, metabolism, substrates, inhibitors, inducers. 


\section{Introduction.}

The development of new drugs always involves preclinical screening, where the main pharmacokinetic, pharmacodynamic, and toxicological properties are studied. These preclinical investigations are based on both in vitro and in vivo models using various animal species. The pig and especially minipigs are increasingly being used in pharmaceutical and toxicological studies, thus their metabolism have been subjected to further research and have recently attracted considerably attention. This biotransformation occurs mainly in the liver, but also the kidneys, skin, lungs, and intestine can be involved. The biotransformation is one of the most important factors that can affect the overall therapeutic and/or toxic response of a drug. It can lead to deactivation / detoxification and excretion of the drug, but also to bioactivation.

The metabolism reactions are generally divided into two groups, phase- 1 and phase- 2 reactions. Phase-1 reactions involve the monooxygenases such as cytochrome P450 complex, and flavin containing monooxygenases (FMO). The cytochrome P450 complex consists of several subfamilies with overlapping but different substrate specificities, different inhibitors and inducers. Several of these subfamilies i.e. CYP1A, CYP2A, CYP2B, CYP2C, CYP2E and CYP3A have been characterized for the pig and minipig (micropig) during the past few years using primary hepatocyte cultures or hepatocyte microsomes $[1,2,3,4,5,6,7,8,9]$. The characterization is done in order to enable the evaluation of the pig as a test animal for human drug metabolism. It is of importance to know if it is possible to extrapolate the result found in pigs to humans. The aim of this 
paper is therefore to review what is known about the porcine P450 enzymes and compare this with their human counterparts. 


\section{Total P450}

The total cytochrome P450 activity in liver microsomes has been estimated for both conventional and Göttingen minipigs. The minipigs contained the highest activity of total P450 (0.81 nmol/prot) and the different strains of conventional pigs contained 0.57 $\mathrm{nmol} / \mathrm{mg}$ prot. [9], 0,22 $\mathrm{nmol} / \mathrm{mg}$ prot [8], and $0.46 \mathrm{nmol} / \mathrm{mg}$, respectively [5]. This shows that the conventional pigs have a P450 activity comparable to the total human $\mathrm{P} 450$ of $0.43 \mathrm{nmol} / \mathrm{mg}$ protein and $0.26 \mathrm{nmol} / \mathrm{mg}$ protein in Caucasian and Japanese, respectively [10], whereas the minipigs total P450 is about $2-3$ fold higher.

\section{CYP1A}

The CYP1A enzymes are involved in the metabolism of several carcinogens such as aromatic and heterocyclic amines, estrogens, mycotoxins and xanthines. These enzymes are also involved in the metabolism of several antidepressant and analgesic drugs. Human CYP1A activity is also present in porcine liver microsomes i.e. ethoxy- and methoxyresorufin O-dealkylation (EROD and MROD) [9]. The O-dealkylation of 7ethoxyresorufin was found to be sex related in minipigs but not in conventional pigs [5]. The activity in female minipigs was 2-4 times higher than in male, whereas the opposite was found for human Caucasians $[10,4]$ where activity in females was 3 times lower than in males. The O-dealkylation ranged from $20-120 \mathrm{pmol} / \mathrm{mg} / \mathrm{min}$ in minipigs and the activities for the different conventional strains were 40 and $100 \mathrm{pmol} / \mathrm{mg}$ prot./min at a substrate concentration of $5 \mu \mathrm{M}[5,9]$. In one study the Vmax for EROD activity was found for both humans and micropigs. The human activities were 25 and 95 
$\mathrm{pmol} / \mathrm{min} / \mathrm{mg}$ prot. for females and males respectively and the porcines were in the same scale 57 and $116 \mathrm{pmol} / \mathrm{min} / \mathrm{mg}$ prot respectively for male and female pigs [4]. The porcine apoprotein level estimated by Western blotting using anti-human antibodies correlated well with enzyme activity $\left(\mathrm{r}^{2}=0.72\right)$ [5], and so did the human activities and apoprotein level $\left(\mathrm{r}^{2}=0.83\right)$ [10], indicating that CYP1A is the main responsible enzyme for this reaction. This was confirmed by inhibition tests both with a chemical inhibitor, $\alpha$ napthoflavone, a known inhibitor of CYP1A, and with antibodies against human CYP1A2 $[11,4]$. Incubation with $1 \mu \mathrm{M} \alpha$-napthoflavone inhibited the CYP1A activity $80-100 \%$ in humans and $60-80 \%$ in minipigs, whereas the antibody inhibited the reaction with only $30-60 \%$ in minipigs, probably due to a decreased specificity because of small differences in protein sequence. The CYP1A activity in pigs can also be increased by the same inducers as the human CYP1A. Lu and Li (2001) [12] compared the in vitro induction of CYP1A using omeprazole as inducer. They found omeprazole induction to be dose-dependent in both human and minipig hepatocytes, but the induction in human hepatocytes was about 3 times more potent than in minipigs. Also $\beta$-napthoflavone (BNF) has been found to be a potent inducer of EROD and a less potent inducer of MROD activity in primary porcine hepatocytes both after 2, 4 and 8 days in culture [2, 13]. The induction could be detected both at the apoprotein level and mRNA level, showing that the induction is transcriptional. Phenobarbital (PB) induction was studied in vivo and an increase in EROD activity and apoprotein level could be detected 24 hrs after ip injection of $80 \mathrm{mg} / \mathrm{kg}[3]$.

A porcine CYP1A1, but no CYP1A2 like cDNA (BAB85660.1) sequence, has been submitted to the GenBank. This cDNA encodes a protein that has about $75 \%$ homology 
to the human CYP1A1. These differences in amino acid sequence may cause the inhibition antibody to have a lower affinity toward this enzyme than to the human protein, resulting in a decrease in inhibition, or another enzyme could be involved in the metabolism.

\section{CYP2A}

The human CYP2A6 accounts for only $4 \%$ of the total P450 content and it metabolizes pharmaceuticals (3\% of drugs metabolized) and compounds of toxicological significance, such as nicotine, nitrosamines and aflatoxin BI. In all studies the porcine CYP2A activity was determined using coumarin as test substrate. As in humans it is found to be the most specific substrate [15]. A sex dependent activity was seen for the coumarin 7-hydroxylase activities in minipig. Göttingen minipig especially showed marked differences, the male having 70 fold lower activity than females $(0.005 \mathrm{nmol} / \mathrm{mg}$ protein, $0.35 \mathrm{nmol} / \mathrm{mg}$ protein) [5]. The Yucatan minipigs showed a 5 fold difference $(0.18 \mathrm{nmol} / \mathrm{mg}$ protein, $0.97 \mathrm{nmol} / \mathrm{mg}$ protein) [4], whereas human males metabolized coumarin 5 times faster than females, $1.3 \mathrm{nmol} / \mathrm{mg} \mathrm{prot} / \mathrm{min}$ and $0.36 \mathrm{nmol} / \mathrm{mg}$ prot./min, respectively [4]. These results also show that humans metabolized coumarin faster than pigs. This was in agreement with results published by Anzenbacher et al, 1998 [1], showing a 5 times higher metabolism in humans than in male minipigs. The metabolism rate for conventional pigs was found to be about $0.33 \mathrm{nmol} / \mathrm{mg}$ prot./min [5], which is in between the values found for male and female minipigs. This is comparable with the published human values varying from 0 to $4.75 \mathrm{nmol} / \mathrm{mg}$ prot./min [14]. The apoprotein 
level in both humans and pigs correlate well with the coumarin -7-hydroxylase activity indicating that the CYP2A is the main responsible enzyme for this activity [10,14]. This is confirmed by inhibition studies, using both inhibitory antibodies against human CYP2A6 and chemical inhibitors. Bogaards et al. 2000 [4] found an inhibition of 60-80\% in minipig and $80-100 \%$ in humans. Another study reported an inhibition of about $90 \%$ for both minipigs and conventional pigs [15]. Nicotine, a substrate for human CYP2A [16], was also tested as substrate for porcine CYP2A and the cotinine formation rate varied from $212-921 \mathrm{pmol} / \mathrm{mg} \mathrm{prot} / \mathrm{min}$ at a substrate concentration of $500 \mu \mathrm{M}$, well above the Km compared to the human mean Vmax value of $466 \mathrm{pmol} / \mathrm{mg} \mathrm{prot} / \mathrm{min}$ with values ranging from $70-2000 \mathrm{pmol} / \mathrm{mg}$ prot $/ \mathrm{min}$ [15]. A positive correlation between cotinine formation and CYP2A protein level was found, but the addition of inhibitory antibody only inhibits the reaction with $40-60 \%$, showing that cotine formation is not as specific a porcine CYP2A reaction as coumarin-7-hydroxylation. The activity of CYP2A could also be inhibited by methoxypsoralen, a known but not specific inhibitor of CYP2A activity [11].

The porcine CYP2A could not be induced in vitro by pyrazole, a known inducer of murine CYP2A, and the activity and apoprotein level of the enzyme decreases rapidly in porcine hepatocyte cultures and it is nearly absent after 48 h. [6]. From in vivo studies, using sexually mature male Göttingen minipigs, it could be seen that castration of the males induce the CYP2A activity of liver microsomes by about 10 times, which proves that the activity of this gene is sexually regulated in minipigs [17]. Positive correlations were found both between enzyme activity, apoprotein level and mRNA, suggesting a transcriptional regulation of the gene. Minipig (Göttingen) and conventional CYP2A 
cDNA sequences have been submitted to the GenBank (accession nr. AY380866 and AB052255 respectively). The wild-type minipig and conventional cDNA sequences encodes proteins that are $99 \%$ homologous and these porcine proteins are $75 \%$ homologous to the human sequence (accession nr. NP0007379). Six substrate recognition sites (SRS) have been identified [18] and they were all found in the porcine proteins [15].

\section{CYP2B}

The content of cytochrome CYP2B6 in humans is only about $1 \%$ of total P450, but the ability of CYP2B6 to metabolize a number of drugs (4\%), such as diazepam, lidocaine and the antineoplastic compounds cyclophosphamide, iphosphamide, and tamoxifen, has attracted considerable attention to this enzyme [19]. Several of the human CYP2B test substrates have been used in order to measure the activity of this enzyme in pigs. The human model substrate is $\mathrm{S}$-mephenytoin measuring the $\mathrm{N}$-demethylation could not be detected in pigs [5]. The 7-ethoxy-4-triflouromethylcoumarin O-dealkylase activity, another CYP2B specific activity, was reported in Yucatan minipig. Females and males contained about the same activity $(0.353 \mathrm{nmol} / \mathrm{mg}$ protein, $0.286 \mathrm{nmol} / \mathrm{mg}$ protein $)$, and they were comparable with the human values [4]. The enzyme activity for both humans and pigs could be inhibited moderately (30-60\%) with anti-rat CYP2B1. The low inhibition percentage may be because the antibody is not species specific or the substrate is only partly metabolized, by CYP2B. The 7-benzyloxyresorufin O-debenzylation has been measured in conventional porcine microsomes [8] and this activity is much higher in pigs than in humans, $370 \mathrm{pmol} / \mathrm{min} / \mathrm{mg}$ prot. compared to the 3.1 and 4.86 $\mathrm{pmol} / \mathrm{min} / \mathrm{mg}$ prot reported by Amato et al and Niva et al. [20, 21]. 
Another CYP2B reaction, the 7-pentoxyresorufin dealkylation activity, could not be detected in pigs by some groups $[1,2,5]$ but could be detected by other groups [3, 13], and this is properly due to differences in assay sensitivity. The activity is about the same in pigs as in humans $(1-11 \mathrm{pmol} / \mathrm{min} / \mathrm{mg}$ prot $)[3,22]$. The reaction can be induced by phenobarbital, a known potent inducer of human CYP2B6, in vivo but not in vitro after 24 hrs. incubation. The in vivo induction can be followed at both the activity, apoprotein and mRNA level [3], indicating that CYP2B catalyses or plays a significantly role in this reaction. Behnia et al 2003 [13 ] showed that the activity of CYP2B can also be induced in vitro by phenobarbital after 8 days in culture, but not after 4 days, where a decrease in activity was seen. The same applies to the benzyloxyresorufine O-dealkylase activity, another a CYP2B reaction. In the GenBank the porcine cDNA and protein sequence can be found for CYP2B22 (A B052256.1). The homology between this protein sequence and the human CYP2B6 is about $72 \%$. These differences in protein sequence may play a role in the differences in substrate specificity between humans and pigs.

\section{CYP2C}

The CYP2C subfamily consists of several enzymes. In humans, 4 different enzymes have been defined [23], CYP2C8, CYP2C9, CYP2C18 and CYP2C19 and all in all they constitute about $20 \%$ of total P450 and metabolizes $35 \%$ of drugs [24]. The CYP2C family metabolizes a range of drugs i.e. losartan, propofol, estrogens and testosterone, mephenotoin, and methadone [19]. The different CYP2C show some cross reactivity toward many of the test substrates, making it difficult to study the different CYP2C activities independently. The CYP2C substrates, tolbutamid and diclofenac, which are 
fairly specific for human CYP2C9, have been tested in pigs. The tolbutamid hydroxylation has been measured in both conventional pigs and minipigs $[8,1]$ and it was shown that the minipigs had lower activity compared to human activity [1]. The activity was not induced in pigs treated with a combination of $\beta$-naphthoflavone, phenobarbital and dexamethasone [8], but the enzyme activity could be inhibited by about $80 \%$ with tranylcypromine, a CYP2C19 inhibitor, whereas the activity was not inhibited by sulphaphenazole, an inhibitor of human CYP2C9 [11]. The diclofenac 4-hydroxylase activity was measured in Yucatan minipigs [4] and estimated to $0.06 \mathrm{nmol} / \mathrm{min} / \mathrm{mg}$ protein for males and $0.02 \mathrm{nmol} / \mathrm{mg} / \mathrm{min}$ for females; these activities were small compared to the human $(1.5-1.9 \mathrm{nml} / \mathrm{mg} / \mathrm{min})$ values. This enzyme activity was inhibited $80-100 \%$ in humans by sulphaphenazole, as expected, but again the porcine activity was only slightly inhibited (20\%), indicating that either the substrates or the inhibitor is not specific for this enzyme in pigs, or the reaction is catalyzed by another enzyme. Mephenytoin 4hydroxylation was used as a test reaction for CYP2C19, but no enzyme reaction could be detected in neither conventional nor minipigs $[8,4,5]$. Immunoblotting, using anti-rat CYP2C11 that hybridize to human CYP2C19, did react with a porcine CYP2C protein and the highest protein level was found for the males. A porcine CYP2C49 cDNA and protein sequence has been submitted to GenBank (AB052258). This sequence shows about $70 \%$ homology to the 4 human CYP2C enzymes. 


\section{CYP2D}

In humans, the CYP2D6 enzyme is one of the most important in drug metabolism. It comprises only $2 \%$ of the total P450 [10], but the enzyme metabolizes about $15 \%$ of all drugs [24], including antidepressants, antipsychotics, and $\beta$-blockers [19] and it shows high interindividual differences in humans due to polymorphisms. The capacity of CYP2D6 should therefore be measured in humans before medication, in order to avoid intoxication or adverse effects, but only few places does this routinely. The porcine CYP2D enzyme has been studied using different substrates and different antibodies giving rise to different results. Three different human test substrates for CYP2D6, debrisoquine, bufuralol and dextromethorphan, have been used to characterize the porcine CYP2D.

It was shown that conventional and Göttingen minipigs did not possess debrisoquine 4hydroxylase activity, but could biotransform dextromethorphan to dextorphan and catalyze the 1-hydroxylation of bufuralol [7]. Bogaard et al [4] have studied the metabolism of bufuralol in Yucatan micropigs and humans and found that the Vmax for micropigs was about 4 times higher than Vmax for humans. No sex differences for neither the pigs nor humans were seen. Immunoblotting, with different antibodies, gave different results. Blotting with polyclonal antibodies gave rise to some very strong bands, whereas blotting with monoclonal antibodies gave no detectable band in one study [7], whereas in another study the same antibody gave rise to a band [8]. These differences could be due to differences in the stringency in the immunoblotting assay or differences in breeds of swine. The metabolism of bufuralol and dextromethorphan was correlated to the immunoblotting result for several different porcine enzymes and a good correlation 
was seen between the enzyme activities and CYP2B protein level in both minipigs and conventional pigs [7]. This indicates that CYP2B and not CYP2D is the main enzyme responsible for these reactions. Inhibition of bufuralol hydroxylation with either the CYP2D inhibitory chemical quinidine or antibody was not possible, whereas the same chemical inhibitor and antibody inhibited the human reaction $60-100 \%$ [4]. This further indicates that the porcine CYP2D is not responsible for the reaction. On the other hand, inhibition with orphenadrine, a human inhibitor of CYP2B6, was successful and dextromethorphan O-demethylation and bufuralol 1-hydroxylation in porcine microsomes could be inhibited by $82 \%$ [7]. In addition pilocarpine and resveratrol inhibitors of CYP2B in mouse and rat respectively, could also inhibit the reaction $70 \%$ and $40 \%$, which indicate that CYP2B is catalyzing this reaction. Further, induction studies performed with hepatocyte cultures incubated with phenobarbital, a CYP2B inducer, showed an increase in metabolism of dextromethorphan [2]. In pig liver, a microsomal CYP2D25 gene catalyzing the vitamin $\mathrm{D}_{3}$ 25-hydroxylase activity has been found. The sequence of this enzyme reveals that it is a member of the CYP2D family [25], as it contains many characteristics of microsomal P450. Alignment of this protein sequence and the human CYP2D6 shows that they share $78 \%$ homology. This high degree of homology may cause the antibodies used in immunoblotting to hybridize to the vitamin $\mathrm{D}_{3}$ 25-hydroxylase protein instead of the CYP2D6 protein. In addition to the vitamin activity, this porcine enzyme can also catalyze the hydroxylation of the drug tolterodine, which is another substrate for human CYP2D6, showing that this enzyme exhibits cross reactivity with human CYP2D6. 


\section{CYP2E}

The human CYP2E1 is of clinical relevance because it is inducible by alcohol and it catalyses the metabolism or bioactivation of many different compounds such as alcohols, ketones, anesthetics and nitrosamines and about $3 \%$ of drugs metabolized by P450 [24]. The enzyme only represents $7 \%$ of total human P450

Chlorzoxazone is the most used human test substrate to estimate the activity of CYP2E1, both in vivo and in vitro [26], as CYP2E1 catalyses the 6-hydroxylation of chlorzoxazone. The chlorzoxazone 6- hydroxylase activity was measured in porcine microsomes and it was found to be sex related in two minipig strains $[4,5]$, the females possessing the highest activity. In conventional pigs and humans, however, no differences between the sexes were seen $[5,27]$. The Göttingen minipig activity was higher (F: 6 $\mathrm{nmol} / \mathrm{min} / \mathrm{mg}$ protein, $\mathrm{M}: 1,23 \mathrm{nmol} / \mathrm{min} / \mathrm{mg}$ protein) [5] than the activity in Yucatan micropigs (F: $0.71 \mathrm{nmol} / \mathrm{min} / \mathrm{mg}$ protein, M: $0.29 \mathrm{nmol} / \mathrm{min} / \mathrm{mg}$ protein) [4] and Yucatan micropig results were lower than human activity $(\mathrm{F}: 2.8 \mathrm{nmol} / \mathrm{min} / \mathrm{mg}$ protein, $\mathrm{M}: 1.3$ $\mathrm{nmol} / \mathrm{min} / \mathrm{mg}$ protein) [4]. The apoprotein level and mRNA concentration of CYP2E was measured in both minipigs and conventional pigs and it showed that there was no correlation between the enzyme activity, mRNA level, and apoprotein concentration, indicating that the regulation of the gene expression could take place at all steps in the biosynthesis of the protein or that this substrate is not specific for the porcine CYP2E [5]. Inhibition studies with antibodies showed that human chlorzoxazone 6-hydroxylase activity could be moderately inhibited by anti-rat CYP2E1, whereas the minipig activity was not inhibited at all [4]. Further ketoconazole and troleandomycin (TAO), two 
CYP3A inhibitors could inhibit the activity up to $70-80 \%[11,4]$. This also indicates that chlorzoxazone is not a specific CYP2E substrate in pigs, but could also be a CYP3A substrate. Inhibition studies using anti- human CYP2A6 antibodies (preliminary results from our laboratory still not published) showed that this antibody could inhibit both the chlorzoxazone hydroxylase, aniline hydroxylase and p-nitrophenol hydroxylase activities, all known human CYP2E1 test reactions and they are all activities found in porcine microsomes [9]. The reactions could be inhibited about 40\%, indicating that also CYP2A plays a significant role in metabolizing these compounds. In vivo induction studies by Desille et al. [3] in pigs with phenobarbital, gave rise to a 5x increase in CYP2E mRNA level and an increase in apoprotein concentration, whereas the metabolism of chlorzoxazone was unchanged. This again shows that CYP2E is not the main enzyme responsible for the metabolism of this substrate. Another in vivo induction study, where minipigs were fed ethanol, an inducer of human CYP2E1, gave a significant induction of CYP2E protein level in castrated pigs. The cDNA sequence and protein sequence of porcine CYP2E has been submitted to GenBank (submission no. AB052259) by M.Kajima. Blast analysis reveals that there is a $75 \%$ (371/493 amino acids) homology between the human and porcine protein sequence. Depending on where the differences are, they can alter the substrate affinity, especially if they are located in the active site i.e. substrate binding site resulting in low affinity toward chlorzoxazone. 


\section{CYP3A}

In humans the CYP3A4 is the most important P450 enzyme comprising about $30 \%$ of total P450 and metabolizing about 36\% [24] of all drugs and it is therefore also the most studied porcine cytochrome. In addition to drugs, this enzyme also converts sex hormones, polycyclic aromatic hydrocarbons and pesticides.

Several different human CYP3A4 test substrates have been used to estimate the activity of porcine CYP3A. The $6 \beta$-hydroxylation of testosterone, the most used reaction in humans to estimate the activity of CYP3A4 [26], has been measured in two minipig strains and conventional pigs. Yucatan micropigs had a higher enzyme activity than Göttingen minipigs and conventional pigs, $4.45 \mathrm{nmol} / \mathrm{min} / \mathrm{mg}$ protein compared to 0.87 $\mathrm{nmol} / \mathrm{min} / \mathrm{mg}$ protein compared to $0.45 \mathrm{nmol} / \mathrm{min} / \mathrm{mg}$ respectively $[4,5]$. These values compare well to the average testosterone 6-hydroxylase activity in humans of 1.69 $\mathrm{nmol} / \mathrm{min} / \mathrm{mg}$ protein. The nifedipine oxidase has also been measured in conventional pigs and minipigs and the activity measured is about the same as the activity obtained in human microsomes average 0.88 and $2.1 \mathrm{nmol} / \mathrm{min} / \mathrm{mg}$ prot for pigs [3, 5] and 1.72 $\mathrm{nmol} / \mathrm{min} / \mathrm{mg}$ prot. in humans [22]. The nifedipine N-oxidation activity correlated well with the testosterone 6-hydroxylase, and these activities again correlated with the apoprotein level measured using anti-human CYP3A in the immune blotting assay [5]. This shows that CYP3A in pigs is the main enzyme responsible for the two reactions. Inhibition studies with ketoconazole, a strong inhibitor of human testosterone hydroxylase, confirms this as ketoconazole could inhibit the testosterone hydroxylation up to $80 \%$ and it was found to be just as potent in pigs as in humans [11, 
4]. Minipig microsomal nifedipine oxidation could be inhibited with troleandomycin, another human CYP3A4 inhibitor. This inhibitor had a lower potency towards the minipig CYP3A than towards the human CYP3A4 [1], which could be due to differences in the amino acid sequence of the protein. The enzyme level and inducibility of the CYP3A enzyme has been studied in vitro in porcine hepatocytes by several groups. In contrast to CYP2A the CYP3A activity remained constant during the first $72 \mathrm{hrs}$. of incubation, and the activity could be induced by rifampicin 3-4 times $[28,6]$, a potent inducer of CYP3A4 in human hepatocyte cultures [29]. Rifampicin also induces both the 1- and 4- hydroxylation of midazolam, whereas dexamethasone, another inducer of human CYP3A4, could induce neither the testosterone hydroxylation nor the midazolam hydroxylation $[2,30,12]$. Phenobarbital, phenytoin, and carbamazepine were also able to induce hydroxylation of testosterone $[1,28]$. Induction with phenobarbital showed that CYP3A could be enhanced both in vitro and in vivo and at both enzyme activity level, apoprotein level, and at mRNA level [3].

The porcine CYP3A gene has been isolated and three different groups have submitted sequences to the GenBank (accession no. AAD04628, BAD06180, All13316). They share $82-83 \%$ homology with the human protein sequence (416-419/503 amino acid). This is a higher homology than appeared for the CYP2B22 and CYP2E, which is reflected in more similar substrate affinities. 


\section{Discussion}

The metabolism and toxicology of new compounds has to be tested and this is done using test animals. When choosing test animals, it is of importance to know if the cytochrome P450 complex of the test animal species resembles that of humans, especially if the compound is going to be used as a human drug. The pig has become an increasingly used test animal, both in pharmacology and toxicology, because it resembles humans in many ways. Therefore, it is of importance to characterize and compare the porcine P450 to the human $\mathrm{P} 450$, in order to be able to extrapolate the results from porcine experiment to humans. Total P450 activity was approximately the same for humans and pigs, depending on the strain of pigs, as the minipigs tend to have a higher total P450 activity than the conventional pigs [5]. Many of the reactions catalyzed by the human enzymes CYP1A2, CYP2A6 and CYP3A4 can also be measured in pigs and the enzyme activities correlate with the apoprotein level found in Western blotting using anti-human antibodies. The reactions could also be inhibited either with inhibitory antibodies or with chemical inhibitors for these enzymes, indicating that these porcine enzyme systems are very similar to the human enzymes. This is, however, not the case for the CYP2D and CYP2E. Most of the human test reactions for these enzymes can also be catalyzed by porcine liver microsomes, but the activity does not correlate with the same apoprotein level. The metabolism of the human CYP2D substrates, bufuralol and dextromethorphan, correlates with the protein level of a CYP2B like protein and can be inhibited by CYP2B inhibitors, suggesting that porcine CYP2B play an important role in catalyzing these reactions. The human test reactions for CYP2E did not correlate with CYP2E protein level, but could be 
inhibited with anti-human CYP2A and with CYP3A chemical inhibitors, indicating that these two porcine enzyme systems catalyze these reactions. Chemical inhibition studies should be carefully evaluated, as most of the chemicals are not specific inhibitors towards one enzyme, but may also inhibit other enzymes, but less potent [30]. Small changes in protein sequence may also result in less potent or no inhibition and the same will apply for inhibitory antibodies, when they are raised against another species. Therefore, a negative result with inhibitory anti-human or anti-rat antibodies does not necessarily imply that the reaction is not catalyzed by the same enzyme in pigs.

In vitro induction of CYP1A is very similar for human and porcine hepatocytes [12], whereas dexamethasone, a human model inducer of CYP3A4, could not induce porcine hepatocytes, in contrast to some of the other mode inducers. In vivo induction studies have also been performed using different inducers i.e. phenobarbital that was found to induce CYP1A, CYP2B, CYP2E and CYP3A measured at protein level [3]. Myers et al [8] also studied in vivo induction at protein level, using a cocktail containing $\beta$ naphthoflavone, phenobarbital and dexamethaxone. Their induction results measured at protein level varied, depending on the antibodies used for immunoblotting. The drawback of these in vivo induction experiments is, however, that the control levels of the induced pigs are not known. This makes it more difficult to find significance in these studies, as the standard deviation is high because of big interindividual differences. A study looking at gender specific induction of CYP2A, however, has overcome this by hepatic resection. The resection makes it possible to measure the control level for the pigs used in the 
experiment [22]. The same applies for inducers, as for inhibitors, they are very rarely specific towards one enzyme, but are able to induce several enzymes [28]. It is therefore of importance, when studying the induction at the protein level, to know the specificity of the antibodies used for immunoblotting and to use species specific antibodies, if available, or to use antibodies specific to species closely related. Looking at induction at the activity level is also difficult, because of the lack of total specificity towards the different substrates. If the induction is transcriptional, it can also be followed at the mRNA level. The induction of mRNA can, in contrast to activity and apoprotein induction, be measured specifically for each enzyme, if the cDNA sequence is known. This will give a more reliable (precise) measure for induction.

Much work has yet to be done in order to fully characterize the porcine P450 enzymes. First of all, sequencing of the enzymes' cDNA that have not yet been sequenced i.e. the different CYP2C, should be done. Then cloning of the sequenced genes and recombinant expression of each P450 enzymes will enable the testing of substrate specificity towards the proteins, one by one. In order to deduce how many \% of total P450 each enzyme account for, one must raise porcine specific immunoblotting antibodies against the different enzymes. Specific porcine inhibitory antibodies against the enzymes will also be needed to estimate how big a role each enzyme plays in the metabolism of different substrates in porcine microsomes.

Evaluation of toxicity and metabolism of new drugs is based on animal test systems and the selection of an appropriate system is of paramount importance. Before testing it is important to try from e.g. QSAR (quantitative structure-activity relationship) analysis to decide which CYP(s) is expected to be involved and then decide on species for the testing 
procedure. It can be concluded, from what is known at present about the porcine CYP enzymes, that the pig is a good test species, if CYP1A, CYP2A and CYP3A are involved in the metabolism of the compound to be tested. 


\section{References}

1. Anzenbacher P, Soucek P, Anzenbacherova E, Gut I, Hruby K, Svoboda Z, Kvetina J. Presence and activity of cytochrome P450 isoforms in minipig liver microsomes. Drug Metab Dispos 1998; 26: 56-59.

2. Monshouwer M, van`t Klooster GAE, Nijmeijer SM, Witkamp RF, van Miert ASJPAM. Characterization of cytochrome P450 enzymes in primary cultures of pig hepatocytes. Toxicol. In vitro 1998; 12: 715-723.

3. Desille M, Corcos L, L`Helgoualc'h A, Fremond B, Campion JP, Guillouzo A, Clement B. Detoxifying activity in pig livers and hepatocytes intended for xenotherapy. Transplantation, 1999; 68(10): 1437-1443.

4. Bogaards JJP, Bertrand M, Jackson P, Oudshoorn MJ, Weaver RJ, van Bladeren PJ, Walther B. Determining the best animal model for human cytochrome P450 activities: a comparison of mouse, rat, rabbit, dog, micropig, monkey and man. Xenobiotica 2000; 30(12): 1131- 1152.

5. Skaanild MT, Friis C. Cytochrome P450 sex differences in minipigs and conventional pigs. Pharmacol \& Toxicol 1999; 85: 174-180. 
6. Skaanild MT, Friis C. Expression changes of CYP2A and CYP3A in microsomes from pig liver and cultured hepatocytes. Pharmacol \&Toxicol 2000; 87: 174-178.

7. Skaanild MT, Friis C. Is CYP2D activity present in pig liver microsomes? Pharmacol \& Toxicol 2002; 91: 198-203.

8. Myers MJ, Farrell DE, Howard KD, Kawalek JC. Identification of multiple constitutive and inducible hepatic cytochrome P450 enzymes in market weight swine. Drug Metab Disp 2001; 29: 908-915.

9. Nebbia C, Dacasto M, Rossetto Giaccherino A, Guiliano Albo A, Carletti M. Comparative expression of liver cytochrome P-450 dependent monooxygenases in the horse and in other agricultural and laboratory species. The Vet. J. . 2003; 165: 53-64.

10. Shimada T, Yamazaki H, Mimura M, Guengerich $P$. Interindividual variations in human liver cytochrome P450 enzyme involved in the oxidation of drugs, carcinogens and toxic chemicals: Studies with microsomes of 30 Japanese and 30 Caucasians. J. Pharm Exp Therap 1994; 270: 414-423.

11. Madden S, Gentile D, Crawford G, Simpson A, and Johnston A. Cytochrome P450 activities in hepatic microsomes from the minipig. ISSX (Int. Soc. Study Xenobiotics) Proceedings 1998; 13: 75 
12. Lu C, Li AP. Species comparison in P450 induction: effects of dexamethasone, omeprazole, and rifampicin on P450 isoforms 1A and 3A in primary cultured hepatocytes from man, Spraque-Dawley rat, minipig, and beagle dog. Chemico-Biol Interac 2001; 134: $271-281$.

13. Behnia K, Bhatia S, Jastromb N, Balis U, Sullivan S, Yarmush M, Toner M. Xenobiotica metabolism by cultured primary porcine hepatocytes. Tissue Engin 2000; 6(5): 467-479.

14. Pelkonen O, Rautio A, Raunio H, Pasanen M. CYP2A6: a human coumarin 7hydroxylalse. Tocicol. 2000; 144: 139-147.

15. Skaanild MT, Friis C. Porcine CYP2A polymorphisms and activity. Accepted for publication in Basic \& Clinical Pharmacology \& Toxicology.

16. Messina ES, Tyndale RF, Sellers EM. A major role for CYP2A6 in nicotine Coxidation by human liver microsomes. J. Pharmacol. Exp. Ther. 1997; 282(3): 16081614

17. Gillberg M, Skaanild MT, Friis C. Changes in hepatic cytochrome 2A, 2E, and 3A expression in the Göttingen minipig following castration. J. Vet Pharm Ther 2003; 26 (suppl): 157. 
18. Lewis DFV, Lake BG. Species differences in coumarin metabolism: a molecular modeling evaluation of CYP2A interaction. Xenobiotica 2002; 32(7): 547-561.

19. Rendic, S. Summary of information on human CYP enzymes: Human P450 metabolism data. Drug Metab. Rev. 2002; 34(1\&2): 83-448.

20. Amato G, Grasso E, Longo V, Gervasi PG. Oxidation of N,N-dimethylformamide and $\mathrm{N}, \mathrm{N}$-deethylformamide by recombinant liver microsomes and human recombinant P4540s. Toxicol. Lettr. 2001; 124: 11-19.

21. Niwa T, Shiraga T, Hashimoto T, Kagayama A.. Effect of cefixime and cefdinir, oral cephalosporines, on cytochrome $\mathrm{P} 450$ activities in human hepatic microsomes. Biol. Pharm. Bull. 2004; 27(1): 97-99.

22. Mutch E, Blain PG, Williams FM. The role of metabolism in determining susceptibility to parathion toxicity in man. Toxicol. Lettr. 1999; 107: 177-187.

23. Guengerich FP. Comparison of catalytic selectivity of cytochrome P450 subfamily enzymes from different species. Chemico Biol Interac 1997; 106: 161-182. 
24. Lewis DFV. Human cytochrome P450 associated with phase 1 metabolism of drugs and other xenobiotics: a compilation of substrates and inhibitor of the CYP1, CYP2 and CYP3 families. Cur. Med. Chem. 2003; 10: 1955-1972.

25. Postlind H, Axen E, Bergman T, Wikvall K. Cloning, structure, and expression of cDNA encoding vitamin $\mathrm{D}_{3}$ 25-hydroxylase. Biochem. Biophys. Res. Com. 1997; 241: 491-497.

26. Yaun R, Madani S, Wei X-X, Reynolds K, Huang S-M. Evaluation of cytochrome P450 probe substrates commonly used by the pharmaceutical industry to study in vitro drug interaction. Drug Met. And Disp. 2002; 30: 1311-1319.

27. Chauret N, Gauthier N, Martin J, Nicoll-Griffth. In vitro comparison of cytochrome P450-mediated metabolic activities in human, dog, cat and horse. Drug Met. Disp. 1997; 25: $1130-1136$

28. Olsen, AK., Hansen, KT., Friis, C. Pig hepatocytes as an in vitro model to study the regulation of human CYP3A4: prediction of drug-drug interaction with 17 alfaethynylestradiol. Chem. Biol. Interact. 1997; 107: 93-108. 
29. Madan A, Graham RA, Carroll KM, Mudra DR, Burton LA, Krueger LA, et al. Effects of prototypical microsomal enzyme inducers on cytochrome P450 expression in cultured human hepatocytes. Drug Met. Disp. 2003; 31(4): 421-431.

30. Hosagrahara VP, Hansen LK, Remmel RP. Induction of the metabolism of midazolam by rifampin in cultured porcine hepatocytes: preliminary evidence for CYP3A isoforms in pigs. Drug Met. Disp. 1999; 27(12): 1512-1518.

31. Sai Y, Dai R, Yang TJ, Krausz KW, Gonzales FJ, Gelboin HV, Shou M. Assesment of specificity of eight chemical inhibitors using cDNA-expressed cytochromes P450. Xenobiotica 2000; 30 (4): 327-343. 